\title{
Validation of S-parameter Power Cable Joint Model on Two Cable Defect Sections
}

\author{
Tze Mei Kuan, Suhaila Sulaiman, Azrul Mohd. Ariffin, Mohd Amjad Ridzuan Radhi \\ Department of Electrical Power Engineering, College of Engineering, \\ Universiti Tenaga Nasional, Jalan IKRAM-UNITEN, 43000 Kajang, Malaysia
}

\begin{tabular}{l} 
Article Info \\
\hline Article history: \\
Received Jun 1, 2018 \\
Revised Jul 21, 2018 \\
Accepted Jul 31, 2018
\end{tabular}

Keywords:

Cables

Defects

Joints

Time Domain Reflectometry

\begin{abstract}
Electricity disruption due to power cable failure is a major challenge to power utility companies worldwide. A technique which provides quick response with accurate result is needed to detect defects along the cable to reduce the disruption time. This paper discusses the application of time domain reflectometry (TDR) technique to identify and locate the defect along a cable. A cable system is modelled in MATLAB/Simulink to replicate the cable configuration with two joints using the scattering parameter (Sparameter). This research studies the fault identification for two degraded sections in a cable by analyzing the reflected signal from the TDR technique. The characteristics of the reflected signal which indicates the defect cable section are discussed in detail in this paper. Results from MATLAB/Simulink simulations are also compared to the experimental results of the same cable configuration. This study shows that the signal reflection characteristics from MATLAB/Simulink simulations are similar to the experimental results. This indicates that the cable model system built using MATLAB/Simulink replicates the actual cable system accurately which can be used for further analysis of cable fault localization.
\end{abstract}

Copyright (C) 2018 Institute of Advanced Engineering and Science. All rights reserved.

\section{Corresponding Author:}

Tze Mei Kuan,

Department of Electrical Power Engineering,

College of Engineering, Universiti Tenaga Nasional,

Jalan IKRAM-UNITEN, 43000 Kajang, Malaysia.

Email: tzemei@uniten.edu.my

\section{INTRODUCTION}

Power cables, switchgears and transformers are among the important assets to power utility companies to ensure a stable power supply to the consumers. Therefore, if fault occurs at any of these assets, electricity disruption happens causing huge impact on both commercial and domestic users. Not only does it cause business losses but human lives are in concern especially critical patients who require 24-hour electric powered life support equipments. Over the years, there have been numerous reports worldwide on electricity disruption especially due to power cable failure [1-6]. Power cable failure has been a major challenge to power utility companies as it is the only medium for power to be supplied to its consumers. Furthermore, power cable fault identification and localization along the cable is a difficult task due to the long cable length installed which can go up to a few kilometres. Power cable failure mainly occurs due to improper installation of the cable joint or the cable itself and cable insulation degradation. Cable joints used to connect the long underground cables may contribute to cable breakdown when the joints are degraded or faulty due to poor workmanship of joint installation since cable jointings are done manually by technicians. Cable insulation degradations such as partial discharge, voids in the insulation and water treeing are common problems faced by the power utility companies [7-10]. It is very important to ensure power cables are well maintained to provide a reliable power system and hence, this research focuses on the technique to identify and locate the fault along a cable. 
Studies in [11-14] have suggested reflectometry techniques due to the fact that these techniques are not destructive compared to other existing techniques as suggested by [7-8], [15-19]. Although techniques in [7-8], [15-19] have been applied by the power utility companies during cable maintenance but most techniques are either destructive, not suitable to be conducted on-site or unable to forecast the cable performance [18-21]. Study in [22] has shown that the time domain reflectometry (TDR) technique is an easy technique which works similarly to the radar system. A pulse is sent to a cable and it is reflected whenever a signal travelling in a cable line encounters an impedance discontinuity where the cable forms an impedance [13]. The location of the impedance change can be identified at the point of reflection shown on the oscilloscope.

This study models a cable system with two joints in MATLAB/Simulink using scattering parameter (S-parameter) to represent the cable joint. The cable system is built and simulated in MATLAB/Simulink with the application of time domain reflectometry (TDR) technique. Studies in [11-12] have modelled the same cable system with $\mathrm{S}$-parameter representing the joint but these investigations are limited to only one degraded cable section in the cable system. This research further investigates the reliability of the cable system with two joints built in MATLAB/Simulink for more than one degraded cable section where in this study is limited to two sections. A number of simulations are conducted on various cable configurations and these results are compared and validated with the actual TDR experimental results from [23].

\section{METHODOLOGY}

This study models three $100 \mathrm{~m} 240 \mathrm{~mm}^{2} 11 \mathrm{kV}$ XLPE cables connected with two good joints as illustrated by Figure 1 using MATLAB/Simulink with S-parameter representing the cable joint. Table 1 tabulates the four simulations conducted where simulation 2 to 4 comprise of two degraded cable sections at different locations. Simulation 1 has the whole good cable configuration to act as the benchmark for analysis of results from degraded cable configurations in simulations 2 to 4 .

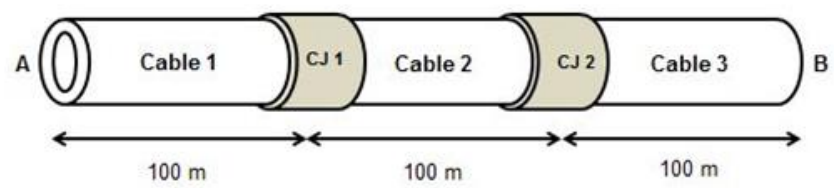

Figure 1. Illustration of three 100m cables connected using two cable joints (CJ 1 and CJ 2)

Table 1. Cable Configuration for MATLAB/Simulink Simulation

\begin{tabular}{|c|c|c|c|c|c|}
\hline \multirow{2}{*}{$\begin{array}{c}\text { Cable } \\
\text { Configuration }\end{array}$} & Cable 1 & \multirow{3}{*}{$\bar{\Xi}$} & \multirow{2}{*}{$\begin{array}{c}\text { Cable } 2 \\
100 \mathrm{~m} \\
\end{array}$} & \multirow{3}{*}{$\stackrel{N}{\stackrel{N}{0}}$} & Cable 3 \\
\hline & $100 \mathrm{~m}$ & & & & $100 \mathrm{~m}$ \\
\hline Simulation 1 & Ideal & & Ideal & & Ideal \\
\hline Simulation 2 & Degraded & $\vec{\pi}$ & Ideal & 2 & Degraded \\
\hline Simulation 3 & Ideal & है & Degraded & है & Degraded \\
\hline Simulation 4 & Degraded & & Degraded & & Ideal \\
\hline
\end{tabular}

Simulations in Table 1 are performed with the application of TDR technique where the TDR works as a linear two-port network in a cable system which can be characterized by scattering matrix (S-parameter) [24]. As this study involves a cascaded system due to two cable joints, the S-parameters is converted to $[\mathrm{ABCD}]$ matrix and expressing it in terms of $\mathrm{S}$-parameters gives:

$$
\left[\begin{array}{ll}
A & B \\
C & D
\end{array}\right]=\left[\begin{array}{ll}
\frac{1+S_{11}-S_{22}-d S}{2 S_{21}} & \frac{1+S_{11}+S_{22}+d S}{2 S_{21}} \\
\frac{1-S_{11}-S_{22}+d S}{2 Z_{0} S_{21}} & \frac{1-S_{11}+S_{22}-d S}{2 S_{21}}
\end{array}\right]
$$

where $d S=S_{11} S_{22}-S_{12} S_{21}$. Expressing the [ABCD] matrix using transmission line parameters with the propagation constant, $\gamma$ of 0.54 and joint characteristic impedance, $Z_{c}$ of $16 \Omega$ gives [25]:

$$
\left[\begin{array}{ll}
A & B \\
C & D
\end{array}\right]=\left[\begin{array}{cc}
\cosh (\gamma l) & Z_{c} \sinh (\gamma l) \\
\frac{\sinh (\gamma l)}{Z_{c}} & \cosh (\gamma l)
\end{array}\right]=\left[\begin{array}{ll}
1.1494 & 9.0660 \\
0.0354 & 1.1494
\end{array}\right]
$$


The S-parameters can then be written as:

$$
[S]=\left[\begin{array}{ll}
S_{11} & S_{12} \\
S_{21} & S_{22}
\end{array}\right]=\left[\begin{array}{cc}
\frac{Z_{0} A+B-Z_{0}^{2} C-Z_{0} D}{d A} & \frac{2 Z_{0}(A D-B C)}{d A} \\
\frac{2 Z_{0}}{d A} & \frac{-Z_{0} A+B-Z_{0}^{2} C+Z_{0} D}{d A}
\end{array}\right]
$$

where $d A=Z_{0} A+B+Z_{0}^{2} C+Z_{0} D$. Therefore, substituting the values for $\mathrm{A}, \mathrm{B}, \mathrm{C}$ and $\mathrm{D}$ gives:

$$
[S]=\left[\begin{array}{ll}
0.0402 & 0.5813 \\
0.5813 & 1.9588
\end{array}\right]
$$

Figure 2 shows the TDR cable system modelled using MATLAB/Simulink with two cable joints represented by the S-parameters.

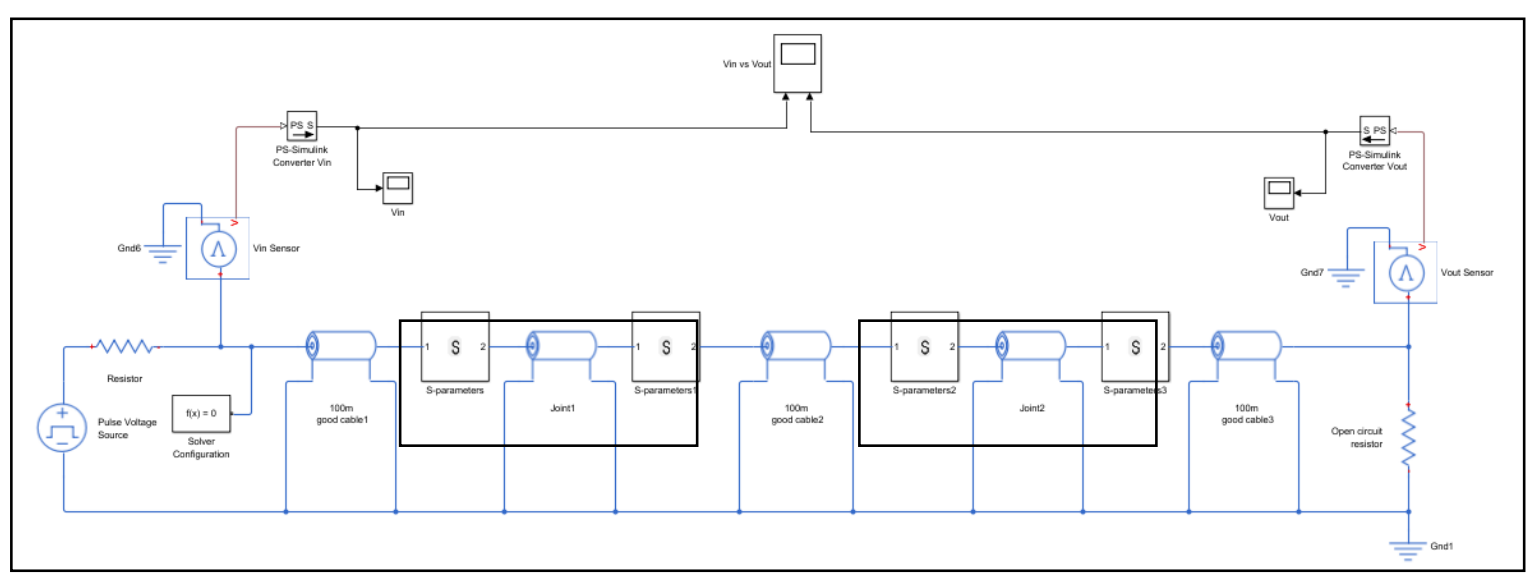

Figure 2. MATLAB/Simulink Cable Model for Cable with Two Joints using S-parameter

Parameters such as relative permittivity, characteristic impedance and time delay are required when modelling the cable system in MATLAB/Simulink. The relative permittivity for an ideal XLPE cable is taken at 2.3 while for a degraded cable is 3.65 [26]. Study in [26] shows that the ideal cable characteristic impedance, $Z_{0}$ ideal of $14.1665 \Omega$ while the degraded cable has the characteristic impedance, $Z_{0}$ of $10.1476 \Omega$.

Simulation results for the cable configurations in Table 1 are then compared and validated with the actual TDR experimental results to investigate the accuracy of cable and joint modelled in MATLAB/Simulink. Experimental results are obtained from study in [23] where tests are conducted using Megger Teleflex SX TDR equipment on cable sample of three $100 \mathrm{~m}$ single core $240 \mathrm{~mm}^{2} 11 \mathrm{kV}$ unarmoured XLPE cables (aluminum conductor) connected with two joints for all experiments. Degraded cable used for the experiment is an insulation degraded cable with semiconductors. All parameters used in the experiment are consistent with the parameters entered in the simulation to ensure comparison of results are conducted on cable with same characteristics.

\section{RESULTS, ANALYSIS AND DISCUSSIONS}

Figure 3 shows the result from simulation 1 in Table 1 where all three cables are in good condition. The two joints located at $100 \mathrm{~m}$ and $200 \mathrm{~m}$ are indicated in the result from the pair of reflections detected at $1 \mu \mathrm{s}$ and $2 \mu \mathrm{s}$, respectively. The locations of these joints at $1 \mu \mathrm{s}$ and $2 \mu \mathrm{s}$ are identified at $100 \mathrm{~m}$ and $200 \mathrm{~m}$, respectively by applying the following time delay equation as explained in [26]:

$$
T D=\frac{l}{\frac{c_{0}}{\mu_{r} \sqrt{\varepsilon_{r}}}}
$$

where $c_{0}$ is the speed of light, $3 \times 10^{8} \mathrm{~ms}^{-1}, \mu_{r}$ is relative permeability of $1.0 \mathrm{Hm}^{-1}$ and $\varepsilon_{r}$ is the relative permittivity of cable insulation, 2.3 for ideal cable and 3.65 for degraded cable. Each joint reflection observed in Figure 3 comprises of a positive pulse followed by a negative pulse with same amplitude. This 
shows that the impedance difference between the cable before and after each joint are the same, indicating all three cable sections are in the same condition. According to studies in [27-28], a degraded cable can be identified from the reflection through a delay since wave propagates slower in degraded cable. However, delay is not observed in both joints reflections from Figure 3. This shows that the three cable sections in simulation 1 are all in good condition which is consistent with the actual cable configuration set in Table 1.

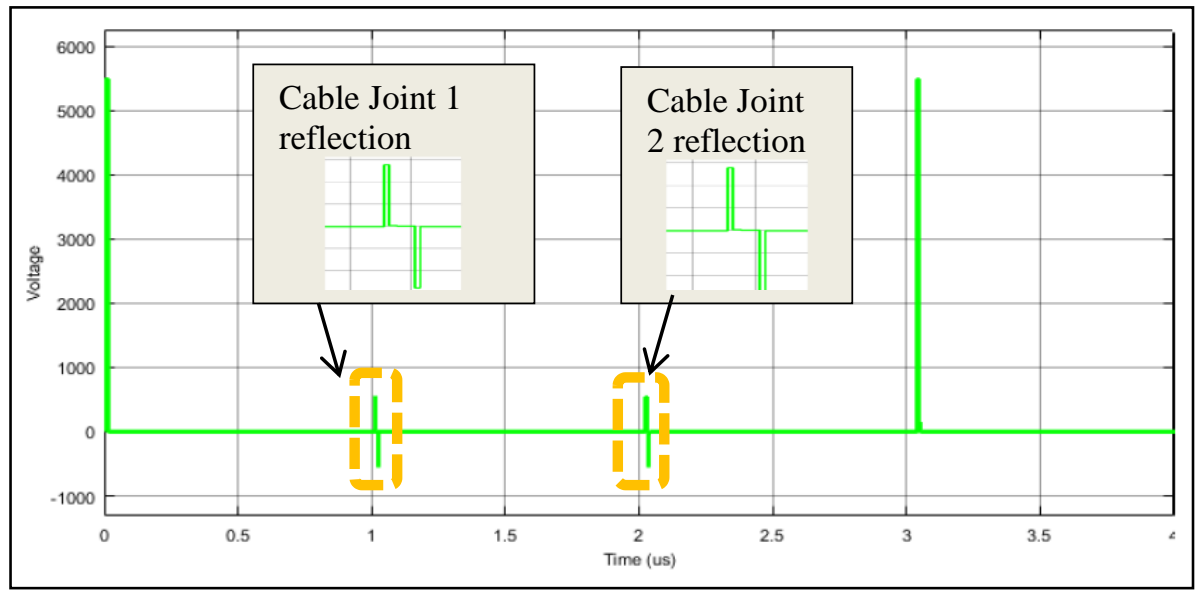

Figure 3. Simulation 1 result

Figure 4 compares the results from simulation 1 with simulation 2 where cables in simulation 2 are degraded in the first and third sections. As described by studies in [27-28], a degraded cable section can be identified from the amplitude of the joint reflections where the reflection closest to the degraded cable shows a higher amplitude than its pair. By observing the results in Figure 4, joint 1 reflection clearly shows higher positive amplitude compared to its negative amplitude. Hence, it can be identified that the first cable section is degraded while the second cable section is in good condition. At the same time at joint 2 reflection, a higher magnitude is observed at its negative reflection while the positive reflection shows smaller amplitude. Thus, it can be concluded that the third cable section is degraded while the second cable section shows consistent result with the first cable joint reflection analysis which indicates a good condition cable.

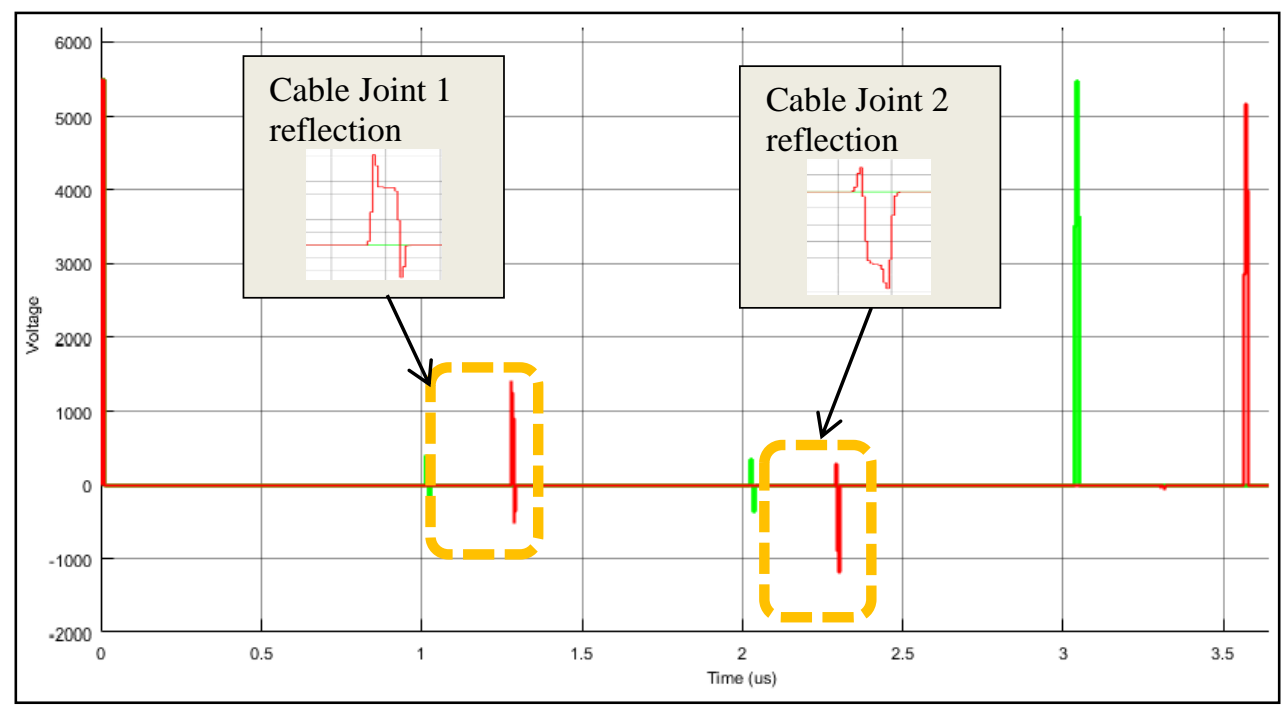

Figure 4. Simulation 1 vs. Simulation 2 results 
Comparison between results from simulation 1 and simulation 3 are shown in Figure 5. Reflection at joint 1 shows a higher negative magnitude compared to its positive magnitude. By applying the earlier hyphothesis, the higher negative reflection magnitude indicates the second cable section is degraded while the first is in good condition. Joint 2 reflection shows a pair of reflections with same magnitude but is detected later than $2 \mu \mathrm{s}$. Therefore, it can be concluded that the second and third cable sections are both having same cable condition. Due to the delay observed, these cables are identified to be in degraded conditions which is also consistent with the actual cable configuration from Table 1.

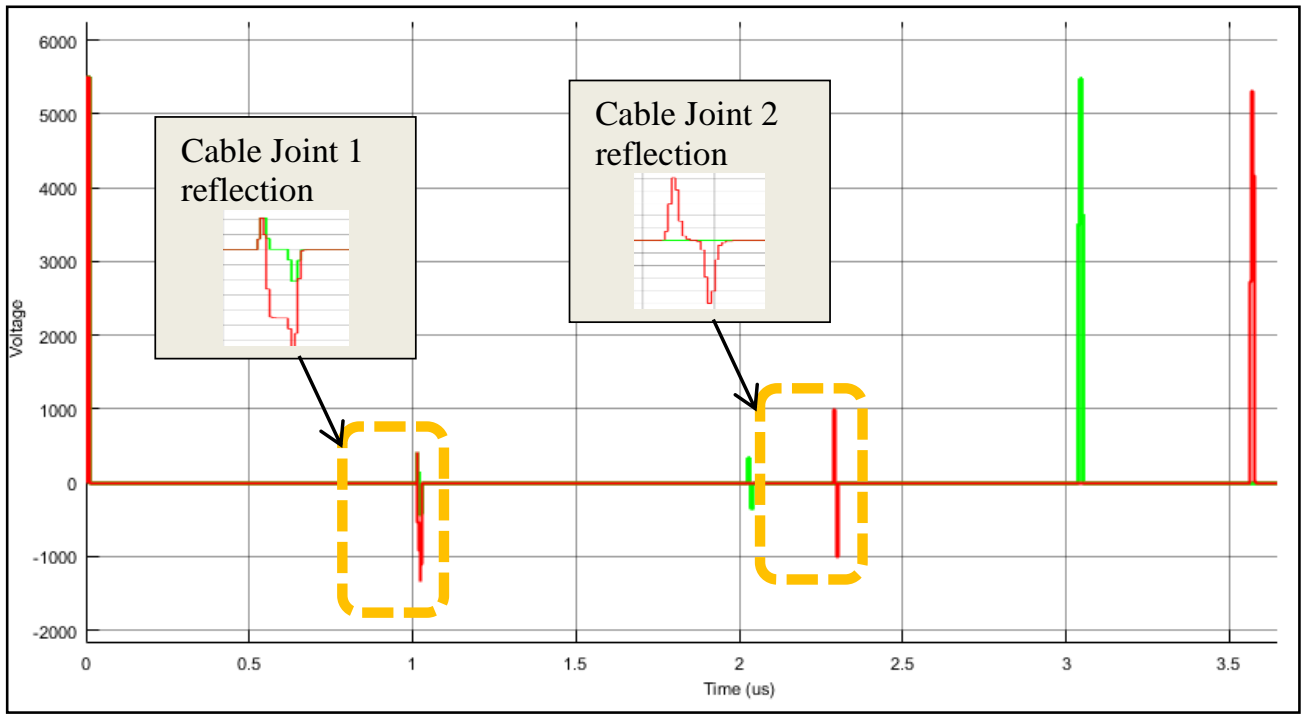

Figure 5. Simulation 1 vs. Simulation 3 results

Results from simulation 1 and simulation 4 are compared and displayed in Figure 6. By analysing the results in Figure 6 using the earlier hyphothesis, the joint 1 reflection which shows a delayed reflection with same positive and negative amplitudes indicates both sections 1 and 2 of the cable are in degraded condition. Joint 2 reflection which shows a higher positive magnitude compared to its negative reflection implies that the third cable section is in good condition while the second cable section is degraded in consistent with the analysis from joint 1 reflection.

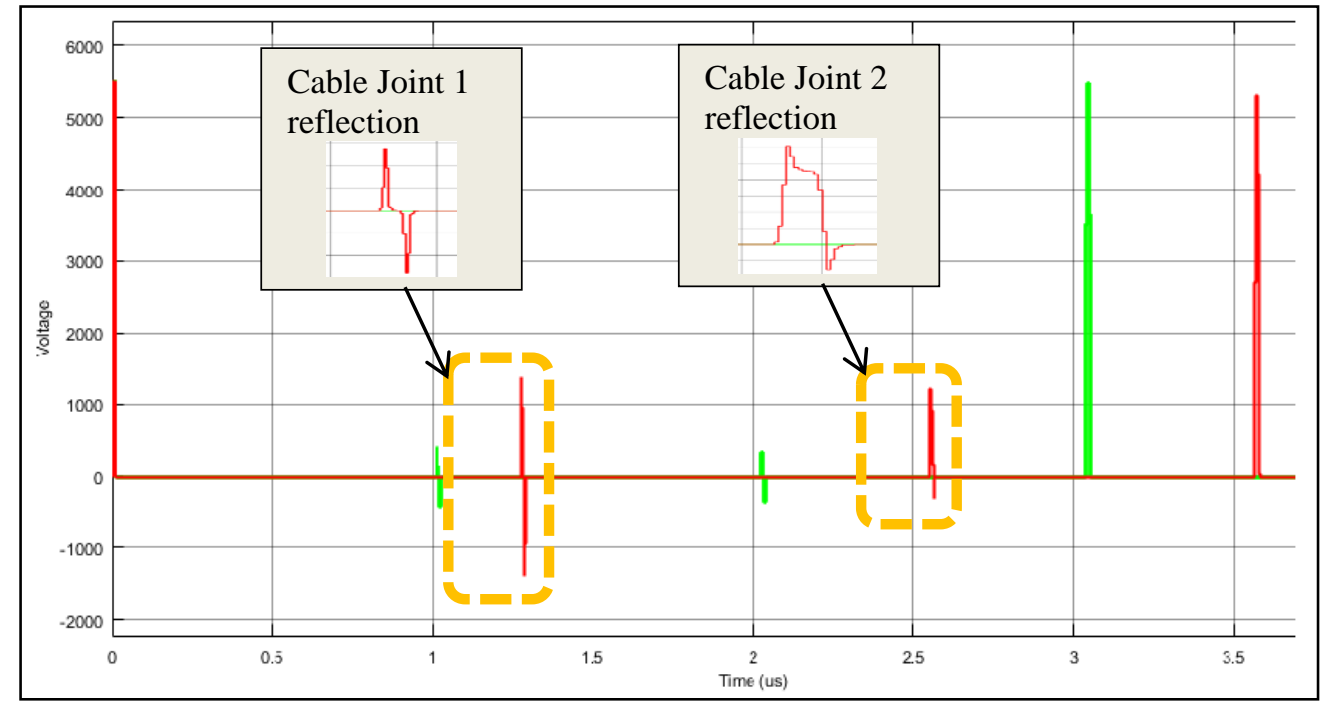

Figure 6. Simulation 1 vs. Simulation 4 results 
Results from Figures 4 to 6 have shown the same characteristics as results from studies in [27-28] which analyse the TDR results from only single degraded section cables. This shows that the TDR technique for the cable system built in MATLAB/Simulink with the S-parameter representing the cable joint is capable of identifying more than one degraded cable section along a cable. These simulation results however are needed to be verified with the experimental results from [23] to ensure the localization of defect cable section is pinpointed correctly on site. Table 2(a) and Table 2(b) compare the joint 1 and joint 2 reflections, respectively using the cable configurations from Table 1. Observations at both cable joints for both simulation and experiment results in Table 2(a) and Table 2(b) have shown same characteristics where the joint reflection closest to the degraded cable section has a higher magnitude in its reflection while showing a delay in its reflection. Same magnitude of joint reflection is also observed when the cable condition before and after the joint are the same but again delay is observed when the two cable sections are both degraded.

The same characteristics of TDR reflections observed for both simulation and experimental results in Table 2(a) and Table 2(b) have therefore imply that the hyphothesis made earlier are true and that the MATLAB/Simulink cable system built with S-parameter representing the cable joint is valid. Thus, the cable model in Figure 2 can be used for future cable defect analysis with jointing.

Table 2. Comparison between Simulation and Experimental results (a) Observation at Cable Joint 1

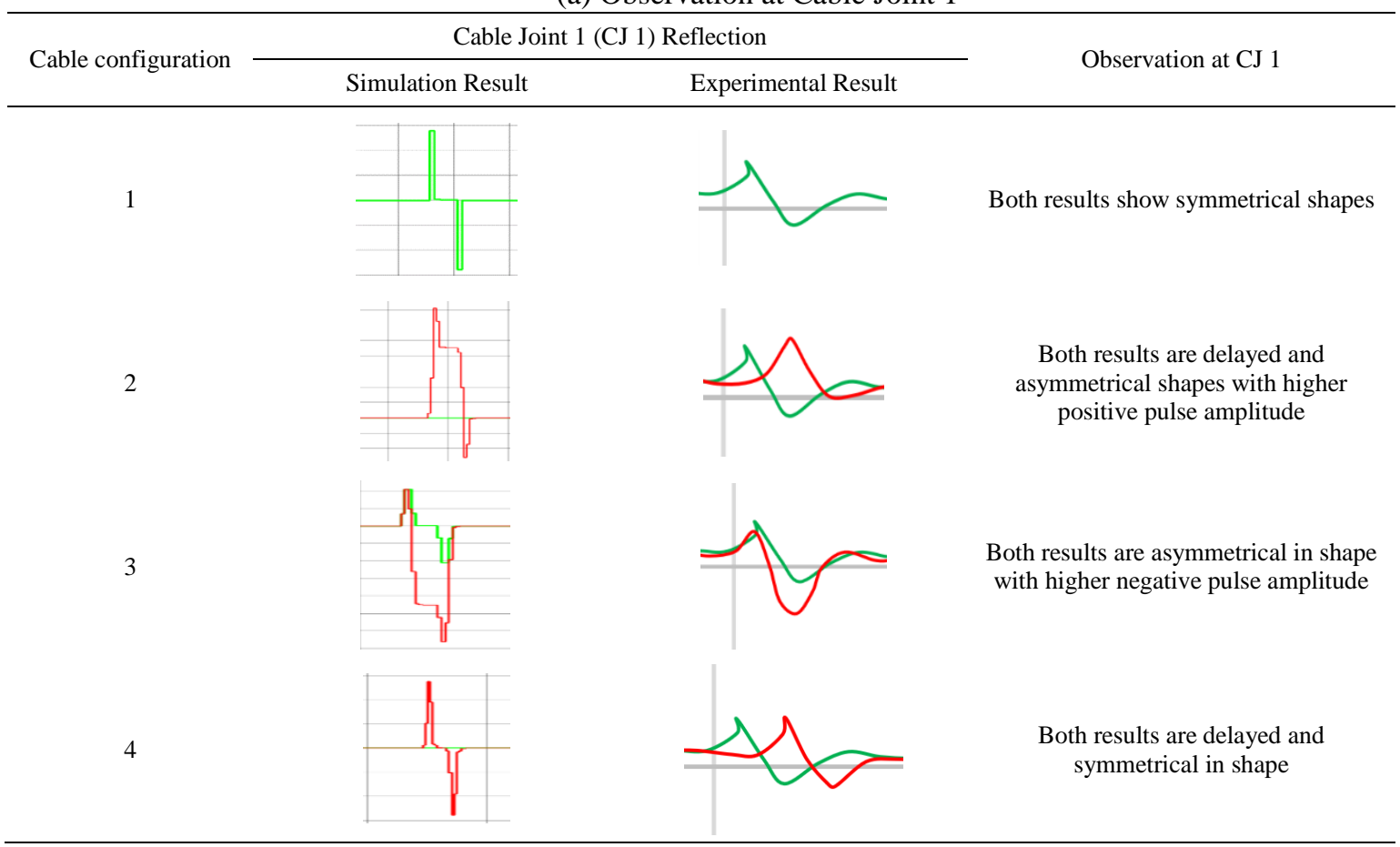

(b) Observation at Cable Joint 2

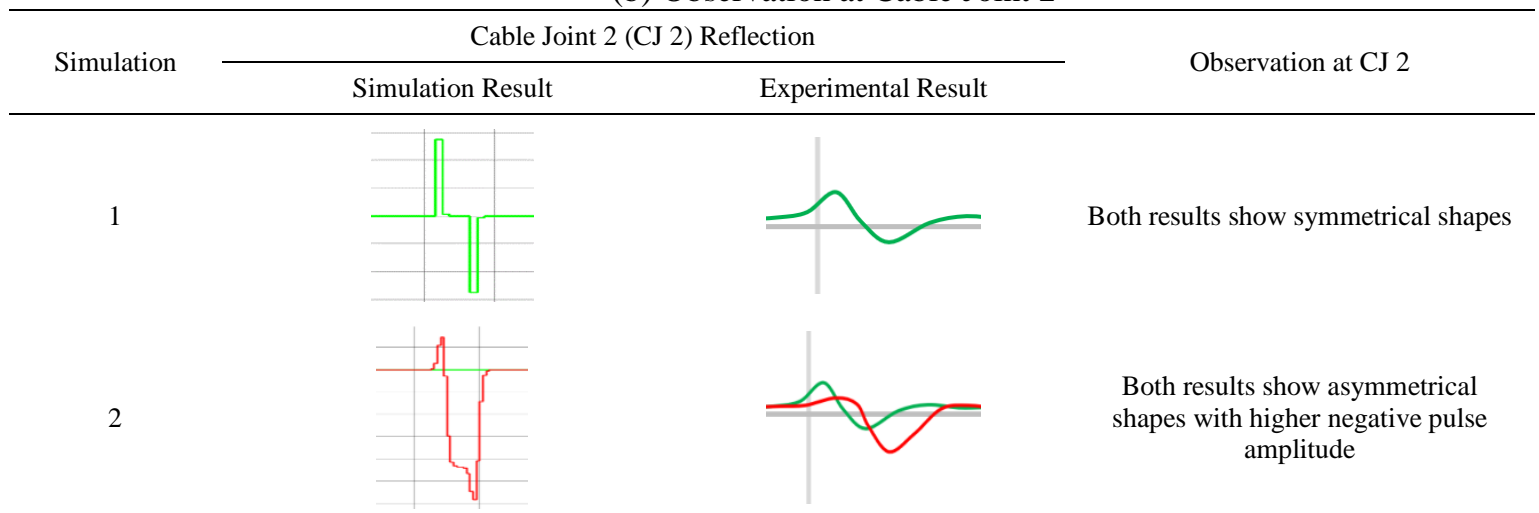




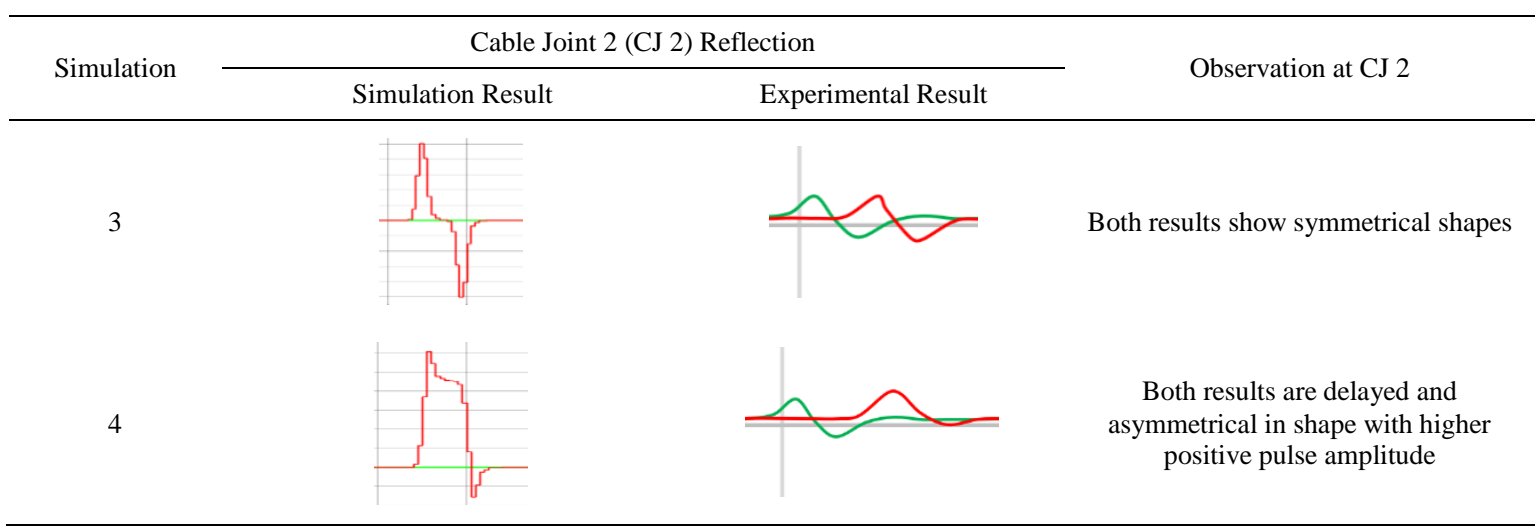

\section{CONCLUSION}

This research verifies the capability of the MATLAB/Simulink cable system built with S-parameter in detecting more than one defect cable sections along a cable. A cable divided into three sections with two connected joints are modelled in MATLAB/Simulink with S-parameter representing each cable joint. Three cable configurations with two degraded cable sections as listed in Table 1 are used for analysis with one whole good cable being simulated as benchmark. Results from simulations 2 to 4 with two degraded cable sections have shown same characteristics with previous studies in [27-28] where analysis were conducted up to one degraded cable section. A degraded cable section can be identified from the joint reflection where the closest reflection to the degraded cable section shows higher reflection amplitude. In the occasion where the cable section before and after the joint are the same, the joint reflection shows same positive and negative amplitudes. However, a delay in the joint reflection is observed when both cable sections are in degraded condition.

Results from simulations 2 to 4 have shown consistency in the reflection characteristics for simulations of more than one degraded cable sections. These simulation results are validated against the experimental results from [23]. Table 2(a) and table 2(b) which compare the results from simulation and experiment have shown same joint reflection characteristics. Hence, these consistencies validate the accuracy of the cable system built in MATLAB/Simulink with S-parameter representing the cable joint. Thus, the cable model in Figure 2 is suggested to be used for future cable defect localization analysis.

\section{ACKNOWLEDGEMENTS}

The authors would like to thank the Ministry of Education, Malaysia for funding this project under the Fundamental Research Grant Scheme (20140121FRGS) and the High Voltage Diagnostics team from TNB Research Sdn. Bhd. for their full support in laboratory facilities, technical support and cable samples.

\section{REFERENCES}

[1] "Breakdowns force National Grid to issue power supply crunch alert," Emily Gosden, The Telegraph News, U.K., 10 May 2016.

[2] "Power rationing flagged for industry after delay in Basslink power cable repairs," Ellen Coulter and Richard Baines, ABC News, Australia, 14 January 2016.

[3] "Cable breakdown may have caused underground blast," John Russell, Indystar, 1 June 2015.

[4] "SMRT points to 3 likely causes of Tuesday's big breakdown," The Straits Times, Singapore, 9 July 2015.

[5] "Underground cable failure responsible for power outage in Ballard," Next Door Media, 25 November 2013.

[6] "Downtown power outage caused by cable failure," Raven Radio Foundation, KCAW, 12 November 2013.

[7] Qiang Gao, Zaiming Yu, Xiaoming Li, Qi Liu, Fang Yuan, Yue Han, Lin Shi, Jixian Shen and Zhaohui Liang, "On Line Monitoring of Partial Discharge in High Voltage Cables," TELKOMNIKA Indonesian Journal of Electrical Engineering, Vol. 4 (3A), September 2016, pp. 108-114.

[8] Zhang Weixia, Zhao Xianping, Zhao Shutao, Yu Hong and Wang Dada, "Study on Partial Discharge Detection of 10kV Power Cable," TELKOMNIKA Indonesian Journal of Electrical Engineering, Vol. 10 (7), November 2012, pp. 1795-1799.

[9] Kai Zhou, Wei Zhao and Xiantao Tao, "Toward Understanding the Relationship between Insulation Recovery and Micro Structure in Water Tree Degraded XLPE Cables," IEEE Transactions on Dielectrics and Electrical Insulation, Vol. 20 (6), December 2013, pp. 2135-2142.

[10] J. Densley, “Ageing Mechanisms and Diagnostics for Power Cables - An Overview," IEEE Electrical Insulation Magazine, Vol. 17 (1), January 2001, pp. 14-22. 
[11] Qinghai Shi and Olfa Kanoun, "A New Algorithm for Wire Fault Location using Time-Domain Reflectometry," IEEE Sensors Journal, Vol. 14 (4), April 2014, pp. 1171-1178

[12] Mostafa Kamel Smail, Lionel Pichon, Marc Olivas, Fabrice Auzanneau and Marc Lambert, "Detection of Defects in Wiring Networks using Time Domain Reflectometry," IEEE Transactions on Magnetics, Vol. 46 (8), August 2010, pp. 2998-3001

[13] Charna Parkey, Craig Hughes and Nicholas Locken, "Analyzing Artifacts in the Time Domain Waveform to Locate Wire Faults,” IEEE Instrumentation \& Measurement Magazine, Vol. 15 (4), 9 August 2012, pp. 16-21

[14] Moon Kang Jung, Yong June Shin and Jin Bae Park, "Application of Time-Frequency Domain Reflectometry based on Multi-band Signal for Detection and Localization of Fault Cable," 2014 14th International Conference on Control, Automation and Systems, 22-25 October 2014, Gyeonggi-do, Korea, pp. 396-401

[15] David L. McKinnon, "Insulation Resistance Profile (IRP) and Its Use for Assessing Insulation Systems," IEEE International Symposium on Electrical Insulation (ISEI), San Diego, June 2010, pp. 1-4.

[16] J. L. Parpal, J. F. Drapeau, C. Potvin, D. Jean, D. Lalancette and P. E. Beaudoin, "Water-Tree Aging Characterization of MV XLPE Cable Insulation using Time Domain Spectroscopy (TDS)," 19th International Conference on Electricity Distribution, CIRED 2007, Vienna, May 2007, pp. 1-4.

[17] C. M. Walton, "Detecting and Locating MV Failure Before It Occurs. Experience with live line partial discharge detection on underground paper insulated $11 \mathrm{kV}$ cables in London," International Conference on Electricity Distribution, CIRED 2001, Amsterdam, June 2001.

[18] Yigang Liu, Xue Chang and Gang Liu, “Analysis of AC Voltage Withstand Test of HV XLPE Power Cable,” IEEE International Conference on Solid Dielectrics, Winchester, U.K., July 2007, pp. 666-668.

[19] Katsumi Uchida, Yoichi Kato, Masahiko Nakade, Daisuke Inoue, Hiroyuki Sakakibara and Hideo Tanaka, "Estimating the Remaining Life of Water-Treed XLPE Cable by VLF Voltage Withstand Tests," Asia Pasific IEEE PES Transmission and Distribution Conference and Exhibition, Vol. 3, October 2002, pp. 1879-1884.

[20] Muhammad Yahya and Muhammad Nazrolni Azmi bin Izani, "Cable Test and Breakdown Voltage Determination of Joysense Cable Insulation,” Indonesian Journal of Electrical Engineering and Computer Science, Vol. 8 (1), October 2017, pp. 177-183.

[21] Jery Althaf, Muhammad Imthiaz and Rejith Raj, "Underground Cable Fault Detection using Robot," International Journal of Electrical and Computer Engineering, Vol. 3 (2), April 2013, pp. 145-151.

[22] J. Wang, P. E. C. Stone, Y-J. Shin and R. A. Dougal, "Application of Joint Time-Frequency Domain Reflectometry for Electric Power Cable Diagnostics,” IET Signal Process, Vol. 4 (4), 4 September 2009, pp. 395-405

[23] Tze Mei Kuan, Azrul Mohd. Ariffin and Maria Madelina Bemmynser Sedau, "Advancement of TDR Technique for Locating Power Cable Insulation Degradation," International Journal on Advanced Science Engineering Information Technology, Vol. 7 (2017), No. 6, pp. 1976-1982

[24] Y. Li, P. Wagenaars, P. A. Wouters, P. C. van der Wielen and E. F. Steennis, "Power Cable Joint Model: Based on Lumped Components and Cascaded Transmission Line Approach," International Journal on Electrical Engineering and Informatics, Vol. 4, No. 4, 2012, pp. 536-552.

[25] Karima Rabaani, Noureddine Boulejfen, "Charcteristic Impedance and Propagation Constant Assessment of Substrate Integrated Waveguide Transmission Line," 11th International Design \& Test Symposium, 2016, pp. 274277

[26] T. M. Kuan, A. Mohd Ariffin and S. Sulaiman, "Signal Analysis to Detect Water Tree Location in Polymeric Underground Cables," 2011 IEEE Student Conference on Research and Development, Cyberjaya, 2011, pp. 277 282.

[27] T. M. Kuan, S. Sulaiman, A. M. Ariffin and W. M. S. W. Shamsuddin, "MATLAB/Simulink Power Cable Modelling for Cable Defects Assessment," Journal of Fundamental and Applied Sciences, Vol. 10 (5S), 22 March 2018, pp. 571-588.

[28] Tze Mei Kuan, Suhaila Sulaiman, Azrul Mohd. Ariffin and Wan Mohamad Shakir Wan Shamsuddin, "Verification of MATLAB/Simulink Power Cable Modelling with Experimental Analysis," International Conference on Electrical Engineering and Computing, Melaka, Malaysia, 24-25 March 2018. 